
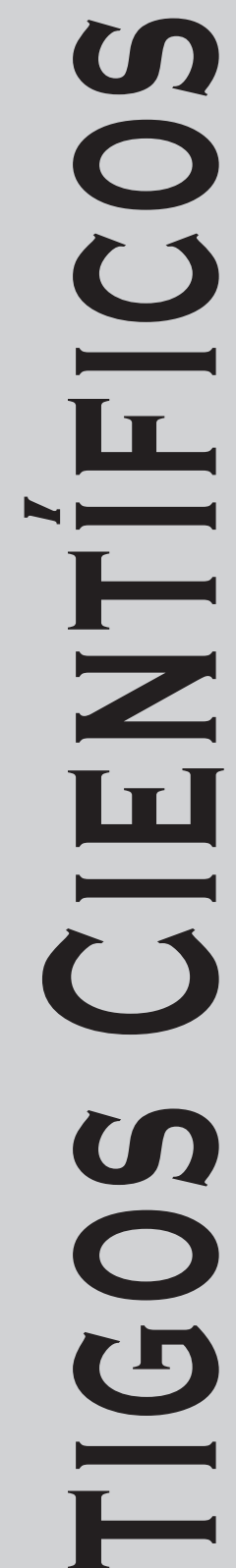
ac

Revista Música Hodie, Goiânia - V.14, 238p., n.1, 2014 


\title{
Estudo Sobre Preferências de Estilo Musical em Estudantes Espanhóis de Ensino Superior do Real Conservatório Superior de Música "Victoria Eugenia”
}

\author{
Oswaldo Lorenzo Quiles (Facultad de Educación y Humanidades de Melilla, Espanha) \\ oswaldo@ugr.es \\ Ángel Luis Pérez Garrido (Real Conservatório Superior de Música “Victoria Eugenia” de Granada, Espanha) \\ angelluisperezgarrido@hotmail.com \\ João Fortunato Soares de Quadros Júnior (Universidade Federal do Maranhão UFMA) \\ joaofjr@gmail.com
}

\begin{abstract}
Resumo: Este estudo objetivou conhecer as preferências musicais de estudantes do Real Conservatório Superior de Música "Victoria Eugenia”, em Granada (Espanha). Contemplando uma amostra de 140 alunos, com idades entre 16 e 31 anos, esta pesquisa adotou uma versão adaptada ao contexto local do Questionário sobre preferência de estilos musicais (Lorenzo; Herrera; Cremades, 2008). Os resultados mostraram que 1) as preferências dos participantes foram similares a de jovens comuns (não estudantes de música), utilizando-a também como fonte de pesquisa; 2) tais preferências sofrem grande influência dos meios de comunicação de massa; 3) os conhecimentos musicais obtidos durante os estudos pré-universitários não foram relevantes para a eleição da música que se deseja consumir.

Palavras-chave: Preferências musicais; Graduação em música; Conservatório; influências musicais formais e informais.
\end{abstract}

Study about the preferences of musical style of Spanish students of higher education at the Conservatory of Music Abstract: This study aimed to know the music preferences of students of the Real Conservatório Superior de Música "Victoria Eugenia", in Granada (Spain). With a sample of 140 students, between 16 and 31 years old, this research used an adapted version of the Questionnaire about musical styles preference (LORENZO; HERRERA; CREMADES, 2008). The results showed that 1) preferences of the participants were similar to young (not music student), also using it as a source of research; 2) such preferences were influenced by the mass media; 3) the musical knowledge obtained during the pre-university studies were not relevant to the choice of music they want to consume.

Keywords: Music preferences; Graduation in music; Conservatory; Formal and informal musical influence.

\section{Introdução}

Diversos trabalhos sobre preferência e hábitos de consumo cultural-musical estão sendo realizados na atualidade, tendo como foco principal estudantes de educação básica e/ou amplos grupos sociais, cujo público participante é formado em sua maioria por adolescentes (BROWN, 2012; CREMADES, 2008; CREMADES; LORENZO; HERRERA, 2010; HARGREAVES; NORTH, 1999; QUADROS JR.; 2013; QUADROS JR.; LORENZO, 2010; 2013; SLATER; HENRY, 2013). Por outro lado, poucos são os estudos sobre esta mesma temática que têm como objeto de pesquisa os conservatórios de música, centros estes os quais apresentam um perfil pessoal e musical de alunado distinto daqueles que pertencem à educação básica, podendo dar uma visão diferente aos resultados convergentes encontrados até o momento com estudantes que têm aulas de música durante sua formação escolar.

Assim sendo, buscou-se nesse trabalho uma aproximação à realidade das preferências de estilos musicais de estudantes de conservatórios de música, que por suas idades vivem imersos na mesma esfera social que outros alunos, mas que musicalmente pertencem a um âmbito formativo muito mais centrado na aquisição de competências prá- 
ticas e interpretativas instrumentais e de conhecimentos musicais disciplinares encontrados em estilos mais conservadores (principalmente aqueles derivados das músicas antiga, barroca, clássica, romântica, impressionista e contemporânea), estilos estes distintos e distantes das músicas urbanas de consumo popular massivo, como, por exemplo, o pop, o rock e o rap.

\section{Classificação geral dos estilos musicais}

Como expõe Martí (2000), no âmbito musical estabelecido pela sociedade contemporânea se deve distinguir entre três grandes blocos estilístico-musicais: a música erudita, a popular e a tradicional. A música erudita, também chamada culta ou séria, é aquela que conta com maior presença no ensino regular na Espanha e se remonta há séculos atrás (CREMADES, 2008); a tradicional é aquela que pesquisadores como Schindler (1941) e Pedrell (1958) dotam de valor folclórico por sua transmissão oral, sem necessidade de estar respaldada por um suporte escrito - partitura -, ainda que, uma vez compilada, se possa transcrever para deixar testemunho da mesma; e a popular não tradicional (urbana, etc.), que é formada por todas as músicas não referenciadas como culta ou tradicional.

Esse trabalho situa a música erudita no âmbito da música clássica; a música tradicional ou de transmissão oral no âmbito das músicas próprias e autóctones de cada região ou lugar do mundo; e a música popular no resto das músicas. Um exemplo de música erudita seria a Sinfonia n. 25, em Sol menor (K183), de Mozart; de música tradicional seria A solteriña, de Sampedro; e de música popular qualquer canção (tema) atual de música rock ou pop dos muitos grupos destes estilos musicais presentes na Espanha ou em outro país de cultura anglo-saxônica, a mais prolífica neste tipo de estilos.

\section{0 termo estilo}

O termo estilo, seu uso e interpretação, abarca distintas áreas de conhecimento geral e de arte e seu significado dependerá de cada uma das épocas históricas nas quais se pretenda explicar. Gombrich (1992), a partir de uma perspectiva das artes plásticas, opina que o estilo configura o nascimento de diferentes artistas que vêm influenciando outros artistas e a sociedade na qual viviam com a exibição de sua arte e certas características individuais peculiares.

Desde a análise da obra literária, se começou a entender o estilo como um processo criador de um autor, levando em consideração o momento de eleição do tema até sua forma de escrever (ALEJO, 2009). Valdés (1995), por outro lado, indica que a forma na qual o artista sente, interpreta e expressa os diferentes valores na arte em relação à sua escola e ao espírito da sua época constitui o estilo, que não só é diferente em cada artista como também depende da sociedade na qual aquele se desenvolve. Schönberg (1911), quase um século antes da reflexão de Valdés, já definia o conceito de estilo como a característica de um artista e a manifestação deste lutando com seus contemporâneos, ficando latente que, independentemente da arte que represente, cada artista procura deixar como legado um estilo pessoal para que possíveis sucessores possam segui-lo e consolidá-lo na história da arte. 


\section{O termo estilo musical}

O conceito de estilo musical é abordado na literatura de uma forma muito ampla e, em diversas ocasiões, confusa, já que se costuma utilizá-lo como sinônimo de forma musical, gênero ou estrutura. É comum que os conceitos de estilo musical e forma musical apareçam juntos, quando na realidade deveriam ser diferenciados de forma clara. Laborda (1996) tenta distinguir esses dois conceitos limitando seus conteúdos para uma melhor compreensão: a forma representaria tanto a estrutura interna nas obras musicais como o esquema preciso em que estas se configuram; têm a ver com os procedimentos, meios e técnicas de composição musical. Os gêneros, por sua vez, são as diversas pautas da criação musical. Por fim, o estilo se refere ao conjunto de meios através dos quais se realiza a obra.

Zamacois (1987) une o conceito de forma e de estrutura, apontando que uma composição musical está configurada por um conjunto organizado de ideias musicais, organização esta que constitui sua própria forma. Esse autor considera forma, estrutura ou arquitetura musical como sinônimas, entendendo que esses conceitos são facilmente de uso privativo do compositor, o qual pode criar uma forma imaginária ou simplesmente adotar uma já consolidada.

Outra aproximação interessante é a que manifesta que a forma nas artes (e especialmente na música) busca, em primeiro lugar, a compreensibilidade. Nenhuma arte é possível sem forma, isto é, sem uma exteriorização estruturada da ideia criadora (SCHÖNBERG, 1963).

Riemann (1943) defende que a forma musical é a coordenação dos diferentes elementos da obra em um todo homogêneo, sendo a estrutura e o estilo definido os que devem fundamentar a utilização dos contrastes, dissidências e oposições. A evolução no pensamento musical do século XX permite ver como se desagrega o conceito de estilo, forma, estrutura e morfologia na história.

Por outro lado, gênero é definido por Fabbri (1981) como um grupo de acontecimentos musicais (reais ou possíveis) cuja direção é governada por um conjunto de regras socialmente aceitas. Para Aucouturier e Pachet (2003), esse termo pode ser utilizado como um conceito intencional ou não-intencional. No primeiro caso, é considerado uma categoria linguística, onde existe um conceito ou uma classificação musical que são produzidos e possivelmente compartilhados por um grupo de pessoas. Por outro lado, como conceito não-intencional, o gênero é uma dimensão de um título musical, tal como timbre, ritmo ou idioma das letras, estando estritamente relacionado com a análise musical.

Por último, estilo musical é definido por Meyer (1956) como um sistema mais ou menos complexo de relações sonoras utilizadas em comum por um grupo de indivíduos, através dos quais se realiza a obra musical. Zorzal (2007) acredita que existam duas tendências acerca do conceito de estilo musical. A primeira compreende esse termo como uma forma de expressão individualizada, a maneira que cada compositor organiza seu discurso. A segunda vertente vê o processo composicional concebido dentro das regras e estratégias onde o compositor toma decisões em função de algum conjunto de limites disponíveis.

Para Tranchefort (1989), estilo é a organização e a personalidade própria de cada obra musical, destacando que diversas obras de um mesmo autor são diferentes entre si graças a uma evolução da personalidade ou por alterações ocasionadas por diferentes agentes externos na vida cotidiana do artista. Meyer (1989, p. 10) defende que "o conhecimento do estilo é usualmente ‘tácito’: isto é, uma questão de hábitos adquiridos (internalizados) adequadamente e apropriadamente postos em prática”. 
Com base no exposto até o momento, foram estabelecidos os seguintes objetivos para essa pesquisa:

- Investigar sobre as preferências musicais que apresentam estudantes de ensino superior em música de Conservatórios;

- Avaliar se o estudo técnico e teórico dos instrumentos musicais de cada aluno constitui em um referente sólido para conformar critérios de consumo musical diferentes a outros jovens da mesma idade, mas não estudantes de conservatório;

- Explorar o grau de influência por parte de agentes como escola, amigos, família e meios de comunicação de massa na eleição de um estilo musical nos estudantes participantes.

\section{Método}

Esse estudo foi realizado no Real Conservatório Superior de Música "Victoria Eugenia”, localizado na cidade espanhola de Granada. Esse Centro é o que possui maior demanda de alunado em toda a Comunidade Autônoma da Andaluzia, possuindo um exame específico para o ingresso de estudantes, o que permite afirmar que este Conservatório se nutre só daqueles alunos que obtiveram pontuações relevantes nas provas para as distintas especialidades, sendo, portanto, alunos com alta competência e qualidade musical, superiores a alunos que seguem seus estudos em outros Centros Andaluzes.

\subsection{Participantes}

Participaram desse trabalho 140 alunos da disciplina-comum Orquestra Sinfônica, lecionada no Real Conservatório Superior de Música "Victoria Eugenia”, de Granada, das seguintes especialidades instrumentais: corda, madeira, metal e percussão. As idades dos participantes estão compreendidas entre 16 e 31 anos, predominando as idades de 16 e 23 anos.

\subsection{Instrumento}

Para a coleta de informação se utilizou uma adaptação ao tipo de estudante e Centro no qual se aplicou o Questionário sobre Preferências de Estilos Musicais (LORENZO; HERRERA; CREMADES, 2008). Esse questionário era composto de uma escala Likert de 1 a 5, variando entre as categorias "Nunca escuto" (1) e "Escuto sempre” (5). O questionário consta de confiabilidade calculada através da prova Alfa de Cronbach (com um valor de 931) e prova de confiabilidade teste-reteste, através da análise de correlação de Pearson entre a primeira e a segunda aplicação do questionário. Também consta de validez de conteúdo mediante juízo de experts e validez de constructo mediante análise fatorial.

\subsection{Procedimento}

A aplicação dos questionários foi realizada em diferentes classes com o conhecimento e consentimento da Equipe Diretiva do Real Conservatório Superior de Música "Victoria Eugenia". 


\section{Resultados}

A análise das respostas dadas ao questionário de Preferências de Estilo Musical se realizou com o pacote estatístico SPSS v.17, desenvolvendo análises estatísticas de distintas naturezas, tratando de verificar si se encontram ou não diferenças estatisticamente significativas entre os distintos níveis que conformam as variáveis de identificação do questionário (idade, gênero, disciplina e curso). Calculou-se, além disso, algumas técnicas de contraste de hipóteses de tipo paramétrico (análise de variância) e não-paramétrico $\left(\chi^{2}\right)$. Esta segunda técnica se aplicou com variáveis de tipo nominal.

\subsection{Valoração dos estilos musicais segundo sua frequência de escuta}

Em primeiro lugar, se apresentam os resultados globais obtidos pelos 49 estilos musicais presentes no instrumento empregado, avaliados em função de sua frequência de escuta. Para isso, se mostram as médias e desvios padrão obtidos por cada um dos estilos que aparecem no estudo empírico.

Tabela 1: Medias e desvios padrão obtidos em cada estilo musical.

\begin{tabular}{|c|c|c|c|}
\hline ESTILO MUSICAL & N & Média & Desvio Padrão \\
\hline Música do Romantismo & 140 & 4 & 0.929 \\
\hline Música Clássica & 139 & 3.63 & 1.023 \\
\hline Trilhas Sonoras Originais & 140 & 3.5 & 1.249 \\
\hline Música do Barroco & 140 & 3.29 & 1.116 \\
\hline Música Nacionalista & 140 & 3.2 & 1.207 \\
\hline Música Impressionista & 140 & 3.16 & 1.077 \\
\hline Música Rock \& Roll & 140 & 3.05 & 1.266 \\
\hline Música Contemporânea & 140 & 3.04 & 1.300 \\
\hline Música Jazz & 140 & 2.97 & 1.303 \\
\hline Música Pop & 140 & 2.94 & 1.242 \\
\hline Música Blues & 140 & 2.86 & 1.230 \\
\hline Música R\&B & 140 & 2.66 & 1.345 \\
\hline Música Salsa & 140 & 2.51 & 1.244 \\
\hline Flamenco & 139 & 2.47 & 1.236 \\
\hline Música de Vanguarda & 139 & 2.47 & 1.175 \\
\hline Música Folclórica & 140 & 2.29 & 1.095 \\
\hline Música do Renascimento & 139 & 2.24 & .899 \\
\hline Música Funk & 139 & 2.22 & 1.214 \\
\hline Música Étnica & 140 & 2.21 & 1.137 \\
\hline Música Soul & 140 & 2.16 & 1.070 \\
\hline Música Swing & 140 & 2.13 & 1.143 \\
\hline Música Heavy Metal & 140 & 2.12 & 1.333 \\
\hline Música New Age & 140 & 2.09 & 1.109 \\
\hline Canção Espanhola & 140 & 2.07 & 1.015 \\
\hline Música Folk & 140 & 2.03 & .996 \\
\hline
\end{tabular}

\begin{tabular}{|c|c|c|c|}
\hline ESTILO MUSICAL & N & Média & Desvio Padrão \\
\hline Música Dance & 140 & 2.01 & 1.184 \\
\hline Música Reggae & 140 & 2 & 1.046 \\
\hline Música Rumba & 140 & 1.99 & .96 \\
\hline Música Hip-Hop & 140 & 1.87 & 1.045 \\
\hline Música Medieval & 140 & 1.84 & .816 \\
\hline Música Punk & 140 & 1.83 & 1.045 \\
\hline Música Tecno & 139 & 1.81 & 1.011 \\
\hline Música Ska & 140 & 1.77 & .977 \\
\hline Música Gregoriana & 140 & 1.76 & .774 \\
\hline Música Drum\&Bass & 140 & 1.74 & .947 \\
\hline Música Rap & 140 & 1.74 & 1.001 \\
\hline Música Nu Metal & 139 & 1.73 & 1.139 \\
\hline Música Break teh Beats & 139 & 1.65 & .931 \\
\hline Música Black Metal & 139 & 1.62 & 1.024 \\
\hline Música anteriores à Idade Média & 140 & 1.61 & .705 \\
\hline Música Country & 139 & 1.59 & .841 \\
\hline Música Breakdance & 140 & 1.59 & .96 \\
\hline Música Death Metal & 140 & 1.59 & 1.011 \\
\hline Música Reguetón & 140 & 1.54 & .94 \\
\hline Música Bacalao & 139 & 1.5 & .829 \\
\hline Música Speed Metal & 140 & 1.49 & .877 \\
\hline Música Trash & 140 & 1.47 & .869 \\
\hline Música Raï & 139 & 1.45 & .753 \\
\hline Música Grindcore & 139 & 1.32 & .651 \\
\hline N válido (segunda a lista) & 131 & & \\
\hline & & & \\
\hline & & \\
\hline
\end{tabular}

Como se pode observar na Tabela 1, os participantes afirmam escutar estilos musicais com diferente intensidade e frequência. A partir das médias obtidas, é possível estabelecer três grandes grupos de estilos de música, de maior a menor intensidade de escuta. Em primeiro lugar, o grupo de maior frequência de escuta integrado por aqueles estilos musicais com médias acima de 3 e com altas porcentagens nas categorias de resposta quase sempre e sempre. Neste grupo se destacam os estilos Música do Romantismo (média de 4); Música Clássica (média de 3.63); e as Trilhas Sonoras Originais (média de 3.5). São também importantes a frequência de escuta da música do Barroco, Nacionalista, Impressionista, 
Rock \& Roll e Contemporânea. Em segundo lugar, se situa um grupo de estilos com médias $<3$ e > 2 e com porcentagens amplas nas categorias de resposta quase nunca, às vezes e quase sempre. Deste grupo se destacam o Jazz (média de 2.97); o Pop (média de 2.94); e o Blues (média de 2.86). O grupo, não obstante, está integrado por muito mais estilos musicais, que vão desde o R\&B até o Reggae. Finalmente, um terceiro grupo, o de menor intensidade de escuta, com médias $<2$ e altas porcentagens de resposta nas categorias nunca e quase nunca. Este grupo estaria encabeçado pela Rumba (média de 1.99) e pelo Hip-Hop (média de 1.87), até a Música Grindcore (média de 1.32).

Com relação aos resultados obtidos pelos desvios padrão calculados, cabe ressaltar as obtidas pelo $\mathrm{R} \& \mathrm{~B}(\mathrm{DP}=1.345)$ e pela Música Grindcore ( $\mathrm{DP}=.651)$. O primeiro dado denota que aquele estilo musical foi o que criou uma maior divergência entre as respostas obtidas, enquanto que o segundo, por sua maior proximidade a 0 , foi o que apresentou maior consenso nas respostas de valoração feitas pelo alunado participante da pesquisa.

\subsection{Resultados descritivos e inferenciais por variável de identificação}

Outra tarefa do presente trabalho de investigação foi determinar como os alunos valoram a frequência de escuta dos distintos estilos musicais contemplados, mas atendendo às variáveis de identificação pelas que se caracteriza tal alunado, ou seja, sua idade, seu gênero e sua especialidade instrumental. Além disso, optou-se também por avaliar se a valoração de escuta dos estilos musicais reportavam ou não diferenças estatisticamente significativas entre as variáveis de estudo.

\subsubsection{Resultados por intervalos de idade}

Foram aplicadas distintas análises de variância (ANOVA), até um total de 49, para comprovar em que estilos musicais se reportavam ou não diferenças estatisticamente significativas $\left(p \leq\right.$. 05) segundo as idade contempladas ${ }^{1}$.

Somente em 5 estilos dos 49 valorados a variável idade apresentou diferenças estatisticamente significativas ( $p \leq .05$ ). Tais estilos foram: Música Medieval, Música Dance, Breakdance, Speed Metal e Trash Metal. Isso significa que a frequência de escuta foi bem distinta nos referidos estilos musicais segundo as distintas faixas etárias comparadas. Dessa forma, pode-se dizer que os alunos compreendidos entre os 28 e 31 anos de idade foram os que declararam escutar com maior frequência Música Medieval (média de 3), frente ao resto de grupo de idades contemplados, provavelmente porque seus gostos musicais estão mais perfilados em função de possuírem idades mais avançadas ou porque se trate de um tipo de alunado que estudou alguma carreira universitária direcionada à Musicologia, História, Filosofia, etc. Contudo, nos outros quatro estilos restantes (Dance, Breakdance, Speed e Trash) foi, pelo contrário, o alunado mais jovem (entre 16 e 19 anos) o qual obteve médias superiores ao resto das idades, isto também propiciado por serem alunos que ainda estavam convivendo com outro tipo de companheiros em seus estudos de Bacharelado: a influência nessa faixa etária por parte das amizades é alta. Este dado se altera quando se terminam os estudos de Bacharelado e o alunado se direciona completamente aos estudos musicais, os quais, junto com novas amizades em classe, condicionam suas preferências para outros estilos musicais. 


\subsubsection{Resultados por gênero}

Tabela 2: Médias e desvios padrão dos diferentes estilos musicais por gênero.

\begin{tabular}{|c|c|c|c|c|}
\hline \multirow{2}{*}{ ESTILOS MUSICAIS } & \multicolumn{2}{|c|}{ HOMEM } & \multicolumn{2}{c|}{ MULHER } \\
\cline { 2 - 5 } & Média & $\begin{array}{c}\text { Desvio } \\
\text { Padrão }\end{array}$ & Média & $\begin{array}{c}\text { Desvio } \\
\text { Padrão }\end{array}$ \\
\hline Música anterior à Idade Média & 1.61 & .740 & 1.65 & .622 \\
\hline Música Gregoriana & 1.76 & .809 & 1.80 & .687 \\
\hline Música Medieval & 1.82 & .837 & 1.93 & .764 \\
\hline Música do Renascimento & 2.19 & .911 & 2.38 & .815 \\
\hline Música do Barroco & 3.22 & 1.13 & 3.48 & 1.06 \\
\hline Música Clássica & 3.61 & 1.06 & 3.70 & .939 \\
\hline Música do Romanticismo & 4.06 & .935 & 3.83 & .903 \\
\hline Música Impressionista & 3.15 & 1.14 & 3.20 & .911 \\
\hline Música Nacionalista & 3.26 & 1.20 & 3.10 & 1.17 \\
\hline Música Contemporânea & 3.09 & 1.34 & 2.95 & 1.17 \\
\hline Música de Vanguarda & 2.46 & 1.22 & 2.53 & 1.06 \\
\hline Flamenco & 2.51 & 1.25 & 2.43 & 1.19 \\
\hline Música Étnica & 2.18 & 1.10 & 2.30 & 1.24 \\
\hline Música Folclórica & 2.27 & 1.10 & 2.33 & 1.09 \\
\hline Canção Espanhola & 2.05 & 1.05 & 2.13 & .939 \\
\hline Música Pop & 2.82 & 1.24 & 3.23 & 1.23 \\
\hline Música Rock \& Roll & 2.95 & 1.24 & 3.30 & 1.32 \\
\hline Música R\&B & 2.62 & 1.36 & 2.78 & 1.31 \\
\hline Música New Age & 2.09 & 1.10 & 2.08 & 1.14 \\
\hline Música Funk & 2.29 & 1.21 & 2.05 & 1.21 \\
\hline Música Punk & 1.82 & 1.08 & 1.85 & .975 \\
\hline Música Tecno & 1.84 & .992 & 1.78 & 1.07 \\
\hline Música Dance & 1.99 & 1.13 & 2.08 & 1.30 \\
\hline Música Bacalao & 1.56 & .92 & 1.35 & .533 \\
\hline Música Drums\&Bass & 1.73 & 1.02 & 1.78 & .733 \\
\hline
\end{tabular}

\begin{tabular}{|c|c|c|c|c|}
\hline \multirow{2}{*}{ ESTILOS MUSICAIS } & \multicolumn{2}{|c|}{ HOMEM } & \multicolumn{2}{c|}{ MULHER } \\
\cline { 2 - 5 } & Média & $\begin{array}{c}\text { Desvio } \\
\text { Padrão }\end{array}$ & Média & $\begin{array}{c}\text { Desvio } \\
\text { Padrão }\end{array}$ \\
\hline Música Break teh Beats & 1.64 & .966 & 1.68 & .859 \\
\hline Música Breacdance & 1.59 & 1.02 & 1.58 & .813 \\
\hline Música Heavy Metal & 2.17 & 1.32 & 1.98 & 1.16 \\
\hline Música Nu Metal & 1.74 & 1.10 & 1.68 & 1.22 \\
\hline Música Death Metal & 1.61 & .988 & 1.55 & 1.08 \\
\hline Música Black Metal & 1.63 & 1 & 1.60 & 1.08 \\
\hline Música Speed Metal & 1.53 & .94 & 1.40 & .709 \\
\hline Música Grindcore & 1.32 & .65 & 1.35 & .662 \\
\hline Música Trash & 1.43 & .87 & 1.50 & .877 \\
\hline Música Jazz & 3.05 & 1.32 & 2.83 & 1.23 \\
\hline Música Blues & 2.94 & 1.24 & 2.73 & 1.17 \\
\hline Música Folk & 2.01 & 1 & 2.10 & .982 \\
\hline Música Country & 1.59 & .86 & 1.60 & .810 \\
\hline Música Salsa & 2.52 & 1.190 & 2.50 & 1.39 \\
\hline Música Soul & 2.16 & 1.09 & 2.20 & 1.01 \\
\hline Música Rumba & 2.01 & .931 & 1.95 & 1.03 \\
\hline Música Reggae & 1.97 & 1.01 & 2.08 & 1.14 \\
\hline Música Hip-Hop & 1.78 & .985 & 2.10 & 1.17 \\
\hline Música Ska & 1.82 & 1.02 & 1.63 & .838 \\
\hline Música Rap & 1.64 & .909 & 1.95 & 1.17 \\
\hline Música Swing & 2.18 & 1.173 & 2.03 & 1.07 \\
\hline Música Sonoras Originais & 3.62 & 1.23 & 3.18 & 1.23 \\
\hline Música Raï & 1.45 & .801 & 1.45 & .639 \\
\hline Música Reguetón & 1.57 & .981 & 1.50 & .847 \\
\hline & & & & \\
\hline
\end{tabular}

Nenhuma análise de variância (ANOVA) resultou estatisticamente significativa para esta variável, razão pela qual não se pode afirmar que o gênero (homem x mulher) resulte relevante no momento de valorar a frequência de escuta dos distintos estilos musicais avaliados.

\subsubsection{Resultados por especialidade instrumental}

Seis dos 49 estilos analisados (preferência de escuta por disciplina) resultaram estatisticamente significativos: Música Barroca, Clássica, Romântica, Étnica, Funk e Trilhas Sonoras Originais. Isso significa que cursar uma ou outra disciplina influi decisivamente na frequência (maior x menor) de escuta dos estilos musicais citados. De fato, nos comentários a seguir se enfatizarão aquelas médias que nos contrastes post-hoc implementados (teste de Tukey) resultaram estatisticamente significativos $(p \leq .05)$ ao serem comparados por binômios.

Aprecia-se como a frequência de escuta de Música Barroca foi muito maior entre o alunado que cursa as disciplinas Viola (média de 3.55), Violino (média de 3.86) e, sobretudo, Oboé (média de 2.5), frente àqueles que cursam Tuba (média de 1.5), Clarinete (média de 2.5) e Percussão (média de 2.5). O resto das disciplinas se mantiveram com médias ligeiramente acima de 3. Estes dados são esperados, já que o alunado que estuda Viola, Violino e Oboé tem entre seu repertório estipulado oficialmente o estudo teórico-prático dos estilos antigos da música, e, organologicamente, na Idade Média e no Barroco ainda não se havia introduzido nas orquestras a Tuba, o Clarinete e a Percussão. 
Com relação à frequência de escuta de Música Clássica, esta foi muito maior entre os alunos que cursam Oboé (média de 3.8), Cello (média de 3.87), Violino (média de 3.91) e, sobretudo, Clarinete (média de 4) e Viola (média de 4.29), dados muito concordantes com os referidos anteriormente, uma vez que o Clarinete surgiu como tal no Classicismo (o auge da orquestra) que, junto com a Forma Sonata, fez crescer de modo veloz a orquestra e é por isso que o naipe de cordas cresce e se reforça. Academicamente, é normal que os alunos mencionados escutem ou consumam música daquela etapa da História da Música, já que é a partir dessas audições que eles conseguem captar importantes elementos técnicos, como o ataque ou emissão de som, fraseado, golpes de arco, etc. No extremo oposto se situam aqueles estudantes que cursam Percussão (média de 2.64) e, sobretudo, Tuba (média de 1.75).

Os alunos de Percussão apresentaram maior escuta para estilos musicais com surgimento posterior ao Classicismo, já que neste período o único instrumento percussivo de uso comum era o tambor, o qual servia como reforço nos "tutti" para confirmar os pontos de suporte na Tônica (I) e na Dominante (V). Os resultados sugerem que esses estudantes prestam maior atenção aos tambores em épocas e estilos posteriores, junto com a pequena percussão, lâminas ou instrumentos com conotações plenamente descritivas dentro de seu repertório de formação acadêmico-instrumental.

Com relação à frequência de escuta de Música do Romantismo, esta foi também sensivelmente maior entre o alunado que cursava Trombone (média de 4.55), Trompa (média de 4.45), Viola (média de 4.5) e Fagote (média de 4.25), frente, fundamentalmente, àqueles que cursavam Oboé (média de 3.6), Tuba (média de 3.25) e, sobretudo, os de Percussão (média de 3). Estes dados não deixam de ser também significativos, já que no Romantismo o trombone começa a ter uma presença forte dentro das orquestras românticas. Algo muito parecido ocorre com a tuba. Por esse motivo, não foi possível obter explicações precisas para os resultados obtidos.

Com respeito à Música Étnica, os alunos de Trompete (média de 3.25) e Percussão (média de 3.33) foram aqueles que afirmaram escutar com maior assiduidade tal estilo musical. Dado significativo, mas não surpreendente, uma vez que a Música Étnica junto com a "fusão" traz consigo o uso de instrumentos típicos de distintas regiões ou países e também a incorporação de instrumentos como o trompete para dar distintas colorações instrumentais à citada música. A percussão também está muito presente, já que a maioria dos instrumentos étnicos são instrumentos de percussão e esta peculiaridade cria de forma crescente o consumo desta música por parte dos alunos de percussão para ver junto com as novas fusões qual é o papel que assume seu instrumento dentro dessas supostas formações orquestrais. Frente a isso se situavam os alunos de Trombone (média de 1.82), Cello e Clarinete (média de 1.8) e, sobretudo, os de Tuba (média de 1.5), com médias baixas e com menor frequência de escuta.

Com relação à Música Funk, foram também os alunos de Trompete (média de 3.11), Percussão (média de 3.25) e de Contrabaixo (média de 3.5) os que afirmaram escutar com maior frequência esse estilo musical. Esse foi um resultado já previsto, pois a Música Funk possui uma importante presença de percussão, baixo ou contrabaixo (dependendo se é acústico ou elétrico), e, nos últimos anos, a incorporação de metais, o que justificaria o seu elevado consumo junto a alunos dessas três especialidades. Por outro lado, os estudantes de Oboé (média de 1.8), Cello (média de 1.53) e Trompa (média de 1.45) apresentaram uma frequência de escuta significativamente menor para esse estilo musical.

Finalmente, com relação às Trilhas Sonoras Originais, os alunos de Trombone (média de 4.18), Fagote (média de 4.25) e Contrabaixo (média de 4.5) foram os que afirmaram 
escutar com maior frequência o citado estilo musical. Por outro lado, com menor frequência de escuta estavam os de Trompa (média de 2.55), Cello (média de 2.4) e Tuba (média de 2.25). Nesse estilo musical é onde se encontra uma maior pluralidade de consumo, já que as trilhas sonoras originais costumam incorporar, além de elementos orquestrais, uma grande variedade de outras músicas. Definitivamente, ela se converte em um estilo de consumo plenamente plural e aberto entre os estudantes.

\subsection{Aspectos que mais influenciam os estudantes na hora de consumir (escutar, comprar ou gravar) a sua música favorita}

Analisam-se neste ponto os resultados globais obtidos pelos aspectos que mais influenciaram a amostra de estudantes participantes neste estudo na hora de escutar, comprar ou gravar a música que eles mais gostavam. Para isso, serão apresentadas as frequências e porcentagens das alternativas de resposta, assim como as médias e desvios padrão obtidos por cada um dos aspectos valorados.

Tabela 3: Médias e desvios padrão obtidos por cada um dos aspectos influentes.

\begin{tabular}{|c|c|c|c|}
\hline Aspectos & $\mathrm{N}$ & Média & Desvio Padrão \\
\hline 0 que aprendeu na Graduação em Música & 135 & 3.53 & 1.145 \\
\hline Os amigos & 139 & 3.45 & 1.309 \\
\hline 0 que aprendeu em Conservatórios prévios à Graduação & 134 & 3.2 & 1.155 \\
\hline Música que baixa na Internet & 129 & 2.96 & 1.497 \\
\hline O que aprendeu em Escola de Música & 62 & 2.94 & 1.503 \\
\hline Família & 139 & 2.76 & 1.393 \\
\hline Rádio & 135 & 2.59 & 1.343 \\
\hline Imprensa escrita & 137 & 2.52 & 1.231 \\
\hline Lugares Públicos & 135 & 2.48 & 1.119 \\
\hline TV & 135 & 2.21 & 1.198 \\
\hline O que aprendeu em geral na educação básica & 137 & 2.1 & 1.031 \\
\hline 0 que aprendeu na aula de música na educação básica & 139 & 1.81 & 1.006 \\
\hline N Válido (segundo a lista) & 59 & & \\
\hline
\end{tabular}

Gráfico 1: Médias obtidas por cada um dos aspectos influentes.

Os resultados descritivos obtidos permitem observar três grandes grupos de aspectos influentes na escuta, compra ou gravação da música que os estudantes participantes nesta pesquisa mais gostavam. O grupo principal estaria integrado por aqueles aspectos com médias superiores a 3 e com altas porcentagens nas categorias quase sempre e sempre: "o que aprendeu na Graduação em Música”, os Amigos e “o que aprendeu no Conservatório prévio à Graduação”. Na sequência estariam aqueles aspectos com médias entre 2.20 e 3, com altas porcentagens de eleição das categorias de resposta às vezes e quase sempre. Este grupo está integrado pelos Lugares Públicos, Imprensa Escrita, Rádio, TV, Família, "o que aprendeu na Escola de Música", assim como "a música que baixa na Internet”. Tal grupo de aspectos poderia ser considerado como de moderada influência. Finalmente, estariam os aspectos de menor influência, grupo formado por aqueles com médias até 2.10 e com altas porcentagens nas categorias de resposta quase nunca e às vezes, fazendo parte desse grupo os itens relacionados à educação básica.

Com referência aos desvios padrão obtidos, a maior divergência foi gerada na valoração do “o que aprendeu na Escola de Música” (DP = 1.50). Por outro lado, os aspectos 
"O que aprendeu em geral na educação básica” e "O que aprendeu na aula de música na educação básica” foram as respostas que obtiveram maior consenso, com desvios padrão em torno de 1.

\section{Conclusões}

As conclusões deste trabalho atendem ao exposto nos três objetivos do estudo. A partir destes, se realiza uma valoração global dos resultados obtidos sobre preferência de estilos musicais nos estudantes de música participantes.

\section{Primeiro Objetivo}

O primeiro objetivo desta pesquisa não apresentou surpresas nos resultados de valoração que se buscava. Os alunos participantes eram jovens que, por sua idade, situação social e proximidade aos meios de comunicação de massa, consumiam música diariamente e de características muito diversas. A música mais escutada por estes responde a gostos muito similares a do resto da juventude de sua mesma idade, ainda que parecesse que os estudos adquiridos e seguidos no Conservatório fizessem que o consumo musical fosse mais racional e técnico, ou seja, utilizassem estas músicas não apenas para o prazer, como também para pesquisar de que forma o seu instrumento principal participava em composições de algum estilo musical especificamente.

\section{Segundo Objetivo}

Relacionados com os resultados do objetivo anterior, se observou que os alunos com idades mais tenras (16-19 anos) e que cursavam o primeiro ano da Graduação em Música, em qualquer especialidade, eram alunos que provinham do Bacharelado e tinham um círculo recente de amizades que consumiam habitualmente os produtos musicais mais presentes nos meios de comunicação. Deste modo, se tratava de alunos que consumiam prioritariamente música relacionada com o Dance, o Breakdance, o Speed Metal e o Trash Metal, o que estava condicionado pelas tendências ou modas com influência juvenil e socialmente aceitas e com hábitos de vida ou de consumo com os quais a juventude se sente bastante identificada.

\section{Terceiro Objetivo}

Finalmente, resultou foi surpreendente comprovar que os alunos participantes neste trabalho não reconheceram o aprendizado obtido nas aulas de música durante a Educação Básica e Bacharelado como influentes na eleição da música que se desejava consumir. Isto situa em uma posição pedagogicamente difícil para o cenário educativo da música no ensino geral pré-universitário na Espanha, o que seria um interessante motivo de estudo em outros trabalhos de pesquisa.

\section{Nota}

${ }^{1}$ Só serão explicitados aqueles estilos que apresentaram um $p \leq .05$, por óbvias razões de espaço. 


\section{Referências}

ALEJO, F. Lengua Castellana y Literatura. Madrid: MAD Editorial, 2009. 596p.

AUCOUTURIER, J.; PACHET, F. Representing musical genre: a state of the Art. Journal of new music research, v.32, n.1, p. 83-93, 2003.

BROWN, R. Music preferences and personality among Japanese university students. International Journal of Psychology, v.47, n.4, p. 259-268, 2012.

CREMADES, R. Conocimiento y preferencias sobre los estilos musicales en los estudiantes de Educación Secundaria Obligatoria en la Ciudad Autónoma de Melilla. Tese de Doutorado. Universidad de Granada, 2008. Melilla: UGR, 2008. 524p.

; LORENZO, O.; HERRERA, L. Musical tastes of secondary school students' with different cultural backgrounds: A study in the Spanish north African city of Melilla. Musicae Scientiae, v.14, n.1, p. 121-141, 2010.

FABBRI, F. A theory of musical genres: two applications. Popular music perspectives, p. 52-81. Disponível em: http://www.tagg.org. Acesso em 20 mai 2009.

GOMBRICH, E. H. Historia del Arte. Madrid: Alianza Forma, 1992. 688p.

HARGREAVES, D.; NORTH, A. The functions of music in everyday life: Redefining the social in music psychology. Psychology of Music, v.27, p. 71-83, 1999.

LABORDA, A. Investigació i intervenció educativa en l'alumnat sord a Psicologia. Barcelona: UAB, 1996. 400p.

LORENZO, O.; HERRERA, L.; CREMADES, R. Investigación sobre preferencias de Estilos Musicales en estudiantes españoles de Educación Secundaria Obligatoria. In: RAMOS, F. (Ed.). Música, Arte, Diálogo, Civilización. Coimbra (Portugal): Center for intercultural Music Arts (CIMA)-Grupo de Investigación HUM-742 D.E.Di.C.A-Universidad de Granada, 2008. p. 301-332.

MARTÍ, J. Más allá del arte: la música como generadora de realidades sociales. Sant Cugat del Vallés: Deriva editorial, 2000. 348p.

MEYER, L. Emotion and meaning in music. Chicago: University of Chicago Press, 1956. 1989. Style and music: theory, history and ideology. London: The University Chicago Press,

PEDRELL, F. Cancionero Musical Popular Español. Barcelona: Editorial Boileau, 1958. 282p.

QUADROS JR., J. Preferencias musicales en estudiantes de enseñanza secundaria en Brasil. El caso de la ciudad de Vitória, Espírito Santo. Tese de Doutorado. Universidad de Granada, 2013. Melilla: UGR, 2013. 669p.

; LORENZO, O. Preferências musicais em estudantes de ensino médio no Brasil: o caso de Vitória, Espírito Santo. Música Hodie, v.10, n.1, p. 109-128, 2010.

. Preferência musical e classe social: um estudo com estudantes de ensino médio de Vitória, Espírito Santo. Revista da ABEM, v.21, n.31, p. 35-50, jul/dez. 2013.

RIEMANN, H. Composición musical: Teoría de las formas musicales. Barcelona: Labor, 1943. 526p.

SCHINDLER, K. Folk music and Poetry of Spain and Portugal. New York: Hispanic Institute in the United States, 1941. 127p. 
SCHÖNBERG, A. Harmonielehre. Madrid: Real Musical, 1911. 546p.

El estilo y la idea. Madrid: Taurus, 1963. 200p.

SLATER, M.; HENRY, K. Prospective Influence of Music-Related Media Exposure on Adolescent Substance-Use Initiation: A Peer Group Mediation Model. Journal of Health Communication: International Perspectives, v.18, n.3, p. 291-305, 2013.

TRANCHEFORT, R. Guía de la Música Sinfónica. Madrid: Alianza Editorial, 1989. 1320p.

VALDÉS, S. C. De la estética y el arte. Guadalajara: Universidad de Guadalajara, 1995. 120p.

ZAMACOIS, J. Curso de formas musicales. Barcelona: Editorial Labor, 1987. 276p.

ZORZAL, R. Referências estilísticas no Estudo V pra violão de Radamés Gnatalli: a imitação como fonte de novidade. Ictus, v.8, n.2, p. 99-108, 2007.

\section{Agradecimentos}

Este trabalho de pesquisa foi financiado pelo II Contrato-Programa de Investigación firmado entre o Vicerrectorado de Política Científica y Investigación da Universidad de Granada e a Facultad de Educación y Humanidades de Melilla (UGR).

Oswaldo Lorenzo Quiles - Professor do Departamento de Didáctica de la Expresión Musical, Plástica y Corporal da Facultad de Educación y Humanidades de Melilla (Espanha), coordenando também o Programa de Doutorado Educación Musical: una Perspectiva Multidisciplinar Doutorado pela Universidad de Granada (Espanha). É doutor em Filosofía e Ciências da Educação pela Universidad Nacional de Educación a Distancia - UNED (Espanha). Publicou diversos artigos em revistas científicas indexadas por Arts \& Humanities Citation Index e Social Science Citation Index.

Ángel Luis Pérez Garrido - Professor Catedrático do Real Conservatório Superior de Música "Victoria Eugenia” de Granada (Espanha). Dirigiu Orquestras na Europa, América e Asia e atualmente é aluno do Programa de Doutorado Educación Musical: una Perspectiva Multidisciplinar Doutorado pela Universidad de Granada (Espanha).

João Fortunato Soares de Quadros Júnior - Professor Adjunto I do curso de Licenciatura em Música da Universidade Federal do Maranhão (UFMA). Doutor em Educação Musical pela Universidad de Granada (Espanha) e Mestre em Música pela Universidade Federal da Bahia (UFBA), publicou em 2009 o livro "Fatores de influência no processo de ensino-aprendizagem musical: o caso da Escola Pracatum”, pela Editora Unimontes, em parceria com os doutores Oswaldo Lorenzo Quiles (Universidad de Granada - Espanha) e Ana Cristina Tourinho (UFBA). 